\title{
Results of a preliminary survey of computer users in psychological laboratories
}

\author{
M. PAVEL \\ New York University, New York, New York 10003
}

\begin{abstract}
A short questionnaire was distributed to a subset of the computer users connected with the National Conference on the Use of On-Line Computers in Psychology to determine the type of computer equipment used by psychologists and the current uses of that equipment. The results of this pilot study are discussed in this paper.
\end{abstract}

Rapid advances in technology have resulted in the widespread use of computers in psychological laboratories. The application of computer technology in psychological research places unique demands on the various systems and their operation. Knowledge of various machines and their current utilization in the field is therefore useful in making decisions regarding the implementation and maintenance of computer-based laboratories.

In order to begin an exploration of machines currently in use, a short questionnaire was distributed to a subset of the users connected with the National Conference on the Use of On-Line Computers in Psychology. The results of this pilot study are reported below. They provide general information on the hardware and software in the field, as well as a summary of the opinions on the usefulness and structure of a users' group.

The questions included in the present study are shown in Table 1. The items are divided into several groups corresponding to hardware, software, type of utilization, and questions regarding the users' groups.

\section{METHOD}

Each completed questionnaire was counted as a single return. The number of returns was distinguished from the number of responses, since most of the questions allowed more than a single response.

The important information is the number of different locations (or users) associated with given equipment or software. Therefore, multiple occurrences of the same item at a location was recorded only as a single occurrence. However, a number of different responses (different processors, software, etc.) received from a single location were all recorded as individual responses.

\section{RESULTS}

Of the 120 questionnaires mailed to a subset of the members of the on-line conference, 23 were returned. During the conference, questionnaire forms were available at the registration desk. As a result, an additional 26 returns were collected, bringing the total up to 49 returns. The results were summarized separately for each question and are reported below.
Table 1

Computer Users' Questionnaire

Hardware at your location (manufacturer, model, and quantity):

1. CPU(s) used

2. Peripherals

3. Technical support and maintenance (in-house, servicc contract)

Software at your location:

4. Operating systems

5. Languages

6. Software support

7. Type of utilization (real-time control, computing)

8. Do you use a computer network or any interconnected processors?

9. How could the various users' groups be more useful to you?

10. Are you in favor of combining the microprocessor and DEC users' groups?

\section{Type of Machine}

The summary of the responses to the first question are shown in Table 2. The most striking result is the number of different machines used in the field. In the 49 returns, there was a total of 43 different systems listed. Therefore, on the average, each respondent had a different system. Of course, this type of average is misleading, since the total number of responses to this question was 122 , indicating that an average user has access to two or three different systems.

Another interesting aspect of these data is the fact that $47 \%$ of the machines in the psychological laboratories are made by the Digital Equipment Corporation (DEC). This ratio is even higher if one examines the proportion of returns (of 49 total) that contained at least one DEC machine. The results show that $57 \%$ of the responding users have access to a DEC machine. Incidentally, 68\% of these users identified PDP-11 as the type of processor.

A summary of the DEC and non-DEC breakdown and overlap of the groups is shown in Table 3 . An interesting feature of these data is the fact that the intersection of the two groups (DEC and non-DEC) is consistent with the assumption that access to DEC and access to non- 
Table 2 Type of Machines

\begin{tabular}{|c|c|c|}
\hline Machine & $\begin{array}{l}\text { Number of } \\
\text { Responses }\end{array}$ & $\begin{array}{c}\text { Percent of } \\
\text { Returns }\end{array}$ \\
\hline DEC 10,20, PDP-5 & 3 & 6.1 \\
\hline PDP-8, PDP-12 & 15 & 30.6 \\
\hline VAX $11 / 780$ & 4 & 8.2 \\
\hline PDP-11/45, 70 & 5 & 10.2 \\
\hline PDP-11/04-60 & 19 & 38.8 \\
\hline PDP-11/03, 23 & 11 & 22.4 \\
\hline LSI-11 Plessey & 3 & 6.1 \\
\hline Terac & 2 & 4.1 \\
\hline Heath & 1 & 2.0 \\
\hline Apple II & 16 & 32.7 \\
\hline Data General Nova & 2 & 4.1 \\
\hline Eclipse & 2 & 4.1 \\
\hline Micronova & 2 & 4.1 \\
\hline PET & 5 & 10.2 \\
\hline TRS 80 & 5 & 10.2 \\
\hline AlM & 3 & 6.1 \\
\hline SORCERER & 3 & 6.1 \\
\hline $\mathbf{Z 8 0}$ & 3 & 6.1 \\
\hline 8080 & 2 & 4.1 \\
\hline INTERDATA $8 / 32$ & 2 & 4.1 \\
\hline NORTHSTAR & 2 & 4.1 \\
\hline ADS & 1 & 2.0 \\
\hline Burroughs 6800 & 1 & 2.0 \\
\hline CDC CYBER & 1 & 2.0 \\
\hline Compucolor & 1 & 2.0 \\
\hline Dynabyte & 1 & 2.0 \\
\hline HP 9845 & 1 & 2.0 \\
\hline KIM 1 & 1 & 2.0 \\
\hline SOLO & 1 & 2.0 \\
\hline Sperry Univac (Varion V76) & 1 & 2.0 \\
\hline TI $99 / 4$ & 1 & 2.0 \\
\hline 6800 & 1 & 2.0 \\
\hline
\end{tabular}

Table 3

DEC vs. Non-DEC Machines

\begin{tabular}{lcc}
\hline \multicolumn{1}{c}{ Machine } & $\begin{array}{c}\text { Number of } \\
\text { Responses }\end{array}$ & $\begin{array}{c}\text { Percent of } \\
\text { Returns }\end{array}$ \\
\hline DEC & 28 & 57 \\
Non-DEC & 35 & 71 \\
DEC Only & 14 & 29 \\
Non-DEC Only & 21 & 43 \\
DEC and Non-DEC & 14 & 29 \\
\hline
\end{tabular}

DEC machines are statistically independent (stronger test of this assertion is not feasible because of the constraints imposed by sampling).

Although the non-DEC group appears to be quite inhomogeneous, there is at least one significant cluster: Use of the Apple II machine appears on 32\% of the returns. Moreover, there are other systems that are based on the same microprocessor CPU (6502) as the Apple II. Thus, there is potential for a significant interaction among the 6502 users. The popularity of these systems is probably due to the availability of both convenient and inexpensive hardware and relatively powerful software (e.g., UCSD PASCAL).

\section{Peripheral Equipment}

The responses to the question concerning peripheral use are shown in Table 4. These results are not as useful as they could be, because most of the respondents did not provide sufficient details, such as manufacturers and model numbers. Moreover, since the responses were to be given in terms of a free recall paradigm, rather than in the form of a recognition task (e.g., checklist), many items were not reported. For example, very frequently occurring items, such as terminals and real-time clocks, were often omitted. Nevertheless, it is quite clear that the most frequently used mass storage media in psychological laboratories are floppy disks. A very interesting positive sign of progress is indicated in that paper tape as a device for storage was reported in only one return. Not so long ago, most of us relied heavily on paper-tape media.

\section{Hardware Support}

The question of hardware support is often one of the most difficult problems in the development and maintenance of a laboratory. Obviously, the most convenient way to assure an effective operation is to carry a service contract. However, there are a number of good reasons why such an approach is not possible.

For one, a service contract is often quite expensive (and for the smaller machines, a service contract may not even be available). The result of this situation is shown in Table 5. Clearly, the majority of maintenance is covered in house, supported by per-call servicing. However, larger machines serving a number of users are more often than not covered by a service agreement.

\section{Operating Systems}

The operating systems that were reported are listed in Table 6. In conjunction with the responses to the first question, the diversity of the operating systems is not surprising. One of the interesting features of these data is the relatively high proportion of UNIX users (UNIX is a registered trademark of the Bell Laboratories). This system, while quite powerful, is not supported by DEC, and it is not particularly well suited for real-time applications. Its disadvantages, however, are well compensated for by

Table 4

Peripheral Equipment

\begin{tabular}{lcc} 
Device & $\begin{array}{c}\text { Number of } \\
\text { Responses }\end{array}$ & $\begin{array}{c}\text { Percent of } \\
\text { Returns }\end{array}$ \\
\hline Terminal & 9 & 18.4 \\
Hard Copy & 16 & 32.7 \\
CRT & 8 & 16.3 \\
Floppy Disk & 31 & 63.3 \\
Hard Disk & 17 & 34.7 \\
Printer & 18 & 36.7 \\
Graphics (Scope) & 13 & 26.5 \\
Plotter & 7 & 14.3 \\
Magnetic Tape Nine Track & 11 & 22.4 \\
$\quad$ DECtape & 3 & 6.1 \\
Cassette & 2 & 4.1 \\
A/D and D/A Convertor & 9 & 18.4 \\
Modem & 8 & 16.3 \\
Paper Tape & 1 & 2.0 \\
Card Reader & 1 & 2.0 \\
\hline
\end{tabular}


Table 5

Hardware Support

\begin{tabular}{lcc}
\hline \multicolumn{1}{c}{ Type } & $\begin{array}{c}\text { Number of. } \\
\text { Responses }\end{array}$ & $\begin{array}{c}\text { Percent of } \\
\text { Returns }\end{array}$ \\
\hline In-House & 30 & 61.2 \\
Service Contract & 17 & 34.9 \\
Third-Party Service Contract & 1 & 2.0 \\
Per Call & 6 & 12.2 \\
\hline
\end{tabular}

Table 6

Operating Systems

\begin{tabular}{lrc}
\hline \multicolumn{1}{c}{ System } & $\begin{array}{c}\text { Number of } \\
\text { Responses }\end{array}$ & $\begin{array}{c}\text { Percent of } \\
\text { Returns }\end{array}$ \\
\hline RT-11 & 17 & 34.7 \\
UNIX & 9 & 18.4 \\
CPM & 5 & 10.2 \\
UCSD PASCAL & 4 & 8.2 \\
Apple DOS & 4 & 8.2 \\
OS 8 & 4 & 8.2 \\
RSX 11 & 3 & 6.1 \\
TRS DOS & 3 & 6.1 \\
Micropolis DOS & 2 & 4.1 \\
NEWDOS & 2 & 4.1 \\
RDOS & 2 & 4.1 \\
AOS & 1 & 2.0 \\
APPLESOFT & 1 & 2.0 \\
DIAL & 1 & 2.0 \\
DOS & 1 & 2.0 \\
FIRST & 1 & 2.0 \\
HDOS & 1 & 2.0 \\
LABSIM, EXPERSIM & 1 & 2.0 \\
RTIOS & 1 & 2.0 \\
RTOS & 1 & 2.0 \\
SOS & 1 & 2.0 \\
TOPS & 1 & 2.0 \\
VMS & 1 & 2.0 \\
VSPC & 1 & 2.0 \\
VORTEX & 1 & 2.0 \\
VTOPS & 1 & 2.0 \\
\hline
\end{tabular}

its flexibility and its ability to provide a very friendly environment.

\section{Languages}

Table 7 is a summary of the answers to the question on the usage of computer languages. The fact that BASIC is currently the most widely used language is probably the result of its simplicity and its availability on the smallest machines in the form of a firmware (read-only memory, ROM). On the other hand, it is quite encouraging that a relatively new but powerful computer language such as PASCAL is already competing very well with the more traditional languages.

\section{Software Support}

Software development and maintenance is often the most expensive aspect of many projects. Nevertheless, only very few responses were made to the question of software support. One of the reasons for the overwhelming prevalence of in-house development efforts is the specific nature of the software needs. Smaller jobs are more easily done by the researcher alone, rather than by describing them to someone else. This situation is not all bad, since the computer is becoming an essential tool to the psychologist and, therefore, a working knowledge is very useful. Larger jobs would be prohibitively expensive and would require the investigator's close supervision anyway.

\section{Type of Utilization}

It is not surprising that the most frequent use of computers in a psychological laboratory is for real-time control. This is shown in Table 8 . While the current second-ranking usage is computing, two new applications are rapidly emerging: word processing and data management. Not only does word processing increase the efficiency of text preparation, but also, in the very near future, it will be possible to communicate with most publishers via machine-compatible media.

\section{Computer Networks}

Table 9 shows that many users reported the use of communication between processors. The most common usage consists of sending data collected in real-time application to a larger machine. The majority of these links are implemented as serial asynchronous interfaces with data rates up to 9,600 baud.

\section{Usefulness of Users' Groups}

This question was included in order to determine possible activities of the microprocessor and DEC users' groups. The majority of users who responded to this question would like to be able to effectively interchange ideas, experiences, and solutions to hardware and software problems. A few of the respondents expressed the desire to share information on a particular system such as Northstar, TRS 80, or Apple/First.

Table 7

Computer Languages

\begin{tabular}{lcc}
\hline Language & $\begin{array}{c}\text { Number of } \\
\text { Responses }\end{array}$ & $\begin{array}{c}\text { Percent of } \\
\text { Returns }\end{array}$ \\
\hline BASIC & 37 & 75.5 \\
FORTRAN & 28 & 57.1 \\
PASCAL & 20 & 40.8 \\
Assembly & 13 & 26.5 \\
C & 7 & 14.3 \\
FOCAL & 7 & 14.3 \\
ALGOL & 3 & 6.1 \\
APL & 2 & 4.1 \\
COBOL & 2 & 4.1 \\
LISP & 2 & 4.1 \\
APPLESOFT & 1 & 2.0 \\
FIRST & 1 & 2.0 \\
FIDO & 1 & 2.0 \\
FORTH & 1 & 2.0 \\
IL8 & 1 & 2.0 \\
RATFOR & 1 & 2.0 \\
\hline
\end{tabular}


Table 8

Type of Utilization

\begin{tabular}{|c|c|c|}
\hline Utilization & $\begin{array}{c}\text { Number } \\
\text { of } \\
\text { Responses }\end{array}$ & $\begin{array}{c}\text { Percent } \\
\text { of } \\
\text { Returns }\end{array}$ \\
\hline Real-Time & 36 & 73.5 \\
\hline Computing & 22 & 44.9 \\
\hline Word Processing and Data Management & 7 & 14.3 \\
\hline Computer-Assisted Instruction & 2 & 4.1 \\
\hline Other & 3 & 6.1 \\
\hline
\end{tabular}

Table 9

Interprocessor Communication

\begin{tabular}{ccc}
\hline & $\begin{array}{c}\text { Number of } \\
\text { Responses }\end{array}$ & $\begin{array}{c}\text { Percent of } \\
\text { Returns }\end{array}$ \\
\hline Yes & 20 & 40.8 \\
No & 16 & 32.7 \\
Soon & 5 & 10.2 \\
\hline
\end{tabular}

Table 10

Should Microprocessor and DEC Groups Combine?

\begin{tabular}{lcc}
\hline & $\begin{array}{c}\text { Number of } \\
\text { Responses }\end{array}$ & $\begin{array}{c}\text { Percent of } \\
\text { Returns }\end{array}$ \\
\hline Yes & 16 & 32.7 \\
No & 11 & 22.4 \\
No Opinion & 22 & 44.9 \\
\hline
\end{tabular}

\section{Combining Microprocessor and \\ DEC Users' Groups}

It has been my experience that many computer users utilize both microprocessors and some other larger machines. In particular, microprocessors are increasingly being used as satellites to more powerful machines. These satellites execute the time-critical real-time tasks, while the larger machines are used to develop programs and to analyze data. Therefore, the users interested in microprocessors may be interested simultaneously in DEC products. The results of this study, shown in Table 10, provide some support for this notion. However, the largest group of users are indifferent to the structure of the groups. This may be due to the fact that a group that meets once a year is unlikely to be useful in solving everyday computer related problems. Incidentally, the "yes" and "no" responses were not correlated with the type of users' machines.

\section{CONCLUSIONS}

The results reported here represent a relatively small sample of computer-based laboratories as of November 1980. Because of the rapid changes in technology and sophistication of users, these results are likely to be obsolete in a year or 2 . For the same reason, it appears to me that the function of the annual National Conference on the Use of On-Line Computers in Psychology will be to address more general questions in various fields. The user groups will be useful only if they can provide a means of continuous interactions among their members. As noted above, a meeting once a year is not sufficient to help users solve their ongoing problems. On the other hand, easy access to a data base containing fairly detailed information on the technology in currently active laboratories would be beneficial to the large population of users. 